\title{
Kentsel Yüzey Isı Adalarının Belirlenmesinde Yer Yüzey Sıcaklık Verilerinin Kullanımı
}

\author{
Müge Ünal Çilek ${ }^{1 *}$ \\ 1* Frrat Üniversitesi, Mimarlık Fakültesi, Peyzaj Mimarlığı Bölümü, Elazı̆̆, Türkiye, (ORCID: 0000-0002-1147-9729), mugeunal@firat.edu.tr
}

(İlk Geliş Tarihi 21 Aralık 2021 ve Kabul Tarihi 26 Ocak 2022)

(DOI: 10.31590/ejosat.1039572)

ATIF/REFERENCE: Ünal Çilek, M. (2022). Kentsel Yüzey Isı Adalarının Belirlenmesinde Yer Yüzey Sicaklık Verilerinin Kullanımı. Avrupa Bilim ve Teknoloji Dergisi. Avrupa Bilim ve Teknoloji Dergisi, (33), 213-222.

$\ddot{O} \mathbf{z}$

Kentsel 1sı adası (KIA) etkisi çevre, enerji ve sağlık sorunlarına neden olmaktadır. Kentsel arazi örtüsü/arazi kullanımı (AÖ/AK) ve değişimleri yer yüzey sıcaklığını (YYS) önemli ölçüde etkilemektedir. Bu çalışmada, Adana kent merkezi için kış ve yaz mevsiminde LANDSAT 8 OLI/TIRS uydusundan yer yüzeyine dayalı ölçümlerden elde edilen YYS ile kentsel AÖ/AK'nın kentsel yüzey 1sı adası (SUHI) üzerindeki etkileri incelenmiştir. YYS sıcaklı̆ğ kış aylarında en yüksek kesikli/süreksiz orta yoğun şehir yapısında (\%30$\% 50)\left(28,4^{\circ} \mathrm{C}\right)$, endüstiyel ve ticari birimlerde $\left(24,1^{\circ} \mathrm{C}\right)$ ve izole yapılarda $\left(18,8^{\circ} \mathrm{C}\right)$ görülmüştür. Yaz aylarında ise en yüksek endüstriyel ve ticari birimlerde $\left(47,8^{\circ} \mathrm{C}\right)$, karayolları ve ilgili alanlarda $\left(42^{\circ} \mathrm{C}\right)$, spor ve eğlence alanlarında $\left(40,1^{\circ} \mathrm{C}\right)$ ve sürekli şehir yapısında $\left(40,0^{\circ} \mathrm{C}\right)$ görülmüştür. Kentsel dokudaki geçirgen yüzeylerin geçirimsiz yüzeylere hılı bir şekilde dönüştürülmesi kentsel yüzey 1Sı dalgalarının ortaya çıkmasına neden olmuştur. Bu çalışmada da geniş geçirimsiz yüzeylere sahip olan havalimanı ile endüstriyel ve ticari birimleri SUHI yoğunluğunun en yüksek olduğu alanlardır. SUHI yoğunluğunun yüksek olduğu bu alanlarda YYS sıcaklığının azaltılması Adana kentinin mekânsal plancılarına gelecekte planlı ve sürdürülebilir kentsel gelişimin sağlanması için iklime duyarlı planlamaya etkin bir şekilde odaklanılması gerekliliğini göstermektedir.

\section{Use of Land Surface Temperature Data to Determine Urban Surface Heat Island}

\begin{abstract}
The urban heat island (UHI) effect causes environmental, energy and health problems. Urban land use/land cover (LULC) and its changes significantly affect land surface temperature (LST). In this study, the effects of the urban LULC on the urban surface heat island (SUHI) were analyzed with the LST obtained from the earth surface-based measurements from the LANDSAT 8 OLI/TIRS satellite in the winter and summer seasons for Adana city center. LST is highest in discontinuous medium density urban fabric (30\% $50 \%)\left(28.4^{\circ} \mathrm{C}\right)$, industrial and commercial units $\left(24.1^{\circ} \mathrm{C}\right)$ and isolated structures $\left(18.8^{\circ} \mathrm{C}\right)$ in winter months. In summer season, higher LST is seen in Industrial and commercial units $\left(47.8^{\circ} \mathrm{C}\right)$, highways and associated land $\left(42^{\circ} \mathrm{C}\right)$, sports and leisure facilities $\left(40.1^{\circ} \mathrm{C}\right)$ and continuous urban fabric $\left(40.0^{\circ} \mathrm{C}\right)$. The rapid transformation of pervious surfaces in the urban fabric into impervious surfaces causes urban surface heat waves. In this study, the airport and industrial and commercial units, which have impervious surfaces, are the areas with the highest SUHI density. Reducing the LST temperature in these areas shows the spatial planners of the city of Adana that it is necessary to focus effectively on climate-sensitive urban planning to ensure planned and sustainable urban development.
\end{abstract}

Keywords: LANDSAT 8, Land Surface Temperature, Surface Urban Heat Island, Adana.

\footnotetext{
*Sorumlu Yazar: mugeunal@ firat.edu.tr
} 


\section{Giriş}

Kentsel 1S1 adası (KIA) etkisi, kentsel alanlardaki hava sıcaklığının veya yer yüzey sıcaklığının (YYS) çevredeki kırsal alanlara göre daha yüksek olduğu durumu ifade eder (Oke, 1973, 1982; Voogt ve Oke, 2003). Kentsel alanda daha yüksek sicaklık bitki örtüsünün büyümesini etkiler (Melaas ve ark., 2016; Zipper ve ark., 2016), hava kirliliğine yol açar (Sarrat ve ark., 2006), enerji tüketimini artırır (Santamouris, 2014; Santamouris ve ark., 2015) ve kent sakinlerinin sağlığını olumsuz etkileyebilir (Vandentorren ve ark., 2006; Tan ve ark., 2010; Dong ve ark., 2014). KIA etkisine temel olarak arazi örtüsündeki (Zhou ve ark., 2016) ve şehirleşmeyle ilişkili arazi kullanımındaki değişiklikler neden olmaktadır (Estoque ve ark., 2017; Du ve ark., 2020; Wang ve ark., 2020; Zhou ve ark., 2021). Ayrica, kentlerdeki türbülanslı ve 1şınımsal değişimleri temsil edebilen bulut miktarı ve rüzgar hızı gibi meteorolojik faktörlerde etkilenmektedir (Morris ve ark., 2001). Son y1llarda özellikle kentleşmenin beraberinde getirdiği kentsel arazi genişlemesinin KIA'yı nasıl etkilediğini araştıran çalışmalar yaygınlaşmıştır (Lu ve ark., 2015; Sejati ve ark., 2019). Araştırma sonuçları, KIA'nın mekânsal dağılımlarının şehirlerin gelişimi veya kentsel genişleme (Zhou ve ark., 2016) ve şehirlerin coğrafi konumu (Ramamurthy ve Sangobanwo, 2016) ile ilgili olduğunu ortaya koymuştur. Sera gazlarının ve antropojenik yüzeylerin (binalardaki cam cepheler, beton, döşeme, yollar, metalden yapılmış yüzeyler vb.) emisyonları, kentsel alanlarda sıcaklık artışının temel nedenleri olarak vurgulanmıştır. Bu faktörler yüzey enerji dengesini değiştirmekte, sıcaklık değişimi ve KIA yoğunluğu şeklinde kendini göstermekte, kentsel ve kırsal iklimi etkilemektedir (Wemegah, 2020).

2018 yılında dünya nüfusunun $\% 55$ 'sinden fazlası şehirlerde yaşıyordu ve bu oranın 2050 yılına kadar \%68'e çıkması beklenmektedir (UN, 2018). Özellikle gelişmekte olan ülkelerdeki hızlı kentleşme süreci, kentsel alanlarda doğal peyzajın daha geçirimsiz bir yüzeye dönüşmesini hızlandırmakta ve bu da radyasyon, termal, nem, pürüzlülük ve emisyon özelliklerini değiştirmektedir (Mathew ve ark., 2016). Kentleşmeden kaynaklanan yüzey değişiklikleri, KIA'ya neden olmaktadır (Estoque ve ark., 2017). Ayrıca bu durum aşırı ve hava olaylarının yoğunlaşmasına (Patz ve ark. 2005), enerji tüketiminin artışına (Hirano ve Fujita, 2012; Santamouris, 2013), hava kalitesinin bozulmasına (Stathopoulou ve ark., 2008; Diem ve ark., 2017), sağlık üzerindeki olumsuz etkiler ve ısıya bağlı ölümlerde artışına (Tan ve ark., 2010; Arifwidodo ve Chandrasiri, 2020; Heaviside ve ark., 2016) neden olmaktadır.

Olumsuz etkilerinin aksine KIA'nın olumlu etkileri de bulunmaktadır. KIA, soğuk iklim bölgelerindeısıtma için daha az enerji tüketimi sağlarken (Sun ve Augenbroe, 2014), aynı zamanda diş mekan konforunu iyileştirmekte, yollardaki olumsuz hava koşullarından kaynaklı tehlikelerinin azalmasını sağlamakta (Stewart ve Oke, 2012) ve soğuk havaya bağlı ölümleri azaltmaktadır (Macintyre ve ark., 2021). Bu özelliklerden dolayı YYS'yi etkileyen mekanizmaları anlamak, KIA uyum stratejilerinin geliştirilmesinde önemli bir rol oynar, çevre dostu ve çevresel açıdan sürdürülebilir kentsel alanların yaratılmasına yardımcı olmaktadır.

YYS, dünyadaki birçok fiziksel, kimyasal ve biyolojik süreç için belirleyici bir faktördür. Uzaktan algılama ile yerel ölçekten küresel ölçeğe kadar YYS'nin tahmini ve yersel-zamansal izlenmesi için etkili bir araçtır (Wan ve Li, 1997; Agarwal ve e-ISSN: 2148-2683 ark., 2014; Yu ve ark., 2014; Zhou ve ark., 2019). YYS aynı zamanda kentsel bir mekan içerisindeki mikro iklimi etkileyen yerel iklim değişikliği olgusunun bir göstergesi olarak da düşünülebilir (Li ve ark., 2013; Rasul ve ark., 2017; Voogt ve Oke, 2003; Weng ve ark., 2011).

Kentleşmenin dünya çapında YYS değişiminin önemli itici güçlerinden biri olduğu belirlenmiştir (Zhou ve ark., 2011; Chen ve ark., 2017; Yang ve ark., 2017; Guo ve ark., 2012; Jiang ve ark., 2015; Tayyebi ve ark., 2018; Fonseka ve ark., 2019). Bu eğilim, gelişmekte olan ülkelerde giderek güçlenen bir eğilime doğru yönelmektedir. Örneğin, Hindistan'daki küçük ve orta ölçekli kentlerdeki plansız ve gelişigüzel kentsel genişleme, zaman içinde kentsel alanlarda LST'nin artmasına neden olmuştur (Das ve Das, 2020a, 2020b). Dutta ve Das'in (2020a) sonuçlarına göre, ortalama YYS'nin, özellikle yerleşim alanlarının hızlı büyümesi nedeniyle (1990) ile 2015 (25 yıl içinde) $1,73{ }^{\circ} \mathrm{C}$ arttığ 1 kaydedilmiştir. Böylece Hindistan'daki küçük ve orta ölçekli şehirlerin genişlemesi, gelişigüzel ve sınırsız büyüme oranları nedeniyle endişe konusu olarak etiketleneceği açıktır (Das ve Das, 2019a). Bu durum ülkemizde de hızlı nüfus artışına sahip olan kentler içinde geçerli bir durumdur. Bu nedenle, kentsel sürdürülebilirliğin yanı sıra kent sakinlerinin refahı için acil önlemlerin uygulanması gerekmektedir. Artan kentleşme nedeniyle arazi örtüsü ve arazi kullanımının (AÖAK) hızlı değişmesi, yalnızca kentsel çevrede termal 1s1 stresi yaratmakla kalmayıp, aynı zamanda kent sakinlerinin yaşam kalitesini de bozmaktadır. Kentsel alanlarda çevresel bozulmanın altyapı gelişimi ile de yakından bağlantılı olduğu tespit edilmiştir (Das ve Das, 2019b). Bu nedenle, hızla kentleşen alanlar üzerindeki YYS modellerinin değerlendirilmesi, kentsel 1s1 stresine karş1 savunmasızlığ anlamak ve etkili arazi kullanım planlaması ve kentsel yüzey 1sı adası etkilerinin azaltılma strajelerinde önemli bir gösterge olacaktır. Bu çalışmada yüksek YYS ve kentsel yüzey 1sı adası (SUHI-Surface Urban Heat Island) yoğunluğu olan bölgeler için yukarıda belirtilen noktalar açısından güçlü bir hipotez sunmaktadır.

Bu doğrultuda çalışmada Adana kentine ait farklı mevsimsel dönemlerde (Aralık-Şubat ve Haziran-Ağustos) yer yüzey sıcaklığı ile kentsel arazi kullanımı arasındaki ilişkinin sayısal olarak belirlenmesi amaçlanmıştır. Yer yüzey sıcaklığının belirlenmesinde 2018 yılına ait Landsat 8 OLI sensörüne ait Red (Band 4), NIR (Band 5), TIR 1 (Band 10) ve TIR 2 (Band 11) bandlarından elde edilen verilerden faydalanılmıştır. Adana kentine ait mevsimlik yüzey sıcaklık haritalarını oluşturmuş ve sigmoid aktivasyonunu kullanarak oluşturulan yüzey sıcaklık haritalarındaki mevsimsel etkiyi indirgemiş ve ardından Adana kentine ait kentsel arazi kullanım verileri ile mevsimsel etkiden arındırılmış yüzey sıcaklık verileri arasındaki ilişkinin detaylıca açıklanması hedeflenmiştir. Çalışma alanı olarak Adana kentinin seçilmesinin ana sebepleri, alanın farklı alan kullanımı ve arazi örtüsü tiplerine sahip olması, mevsimsel sıcaklık farklılıklarının yüksek olması, alan kullanımı ve arazi örtüsündeki yer yüzey sıcaklığının mevsimlere göre nasıl değiştiğinin tespit edilebilmesi için veri teminin kolay olması olarak sıralanabilir.

\section{Materyal ve Metot}

\section{1. Çalışma alanı}

Türkiye'de, kentsel yerleşimlerin yüksek yoğunluğu ile karakterize edilen bir kentsel bağlam olan Adana kenti, en yoğun gelişmiş ve beşinci kalabalık bölgedir (Şekil 1). 

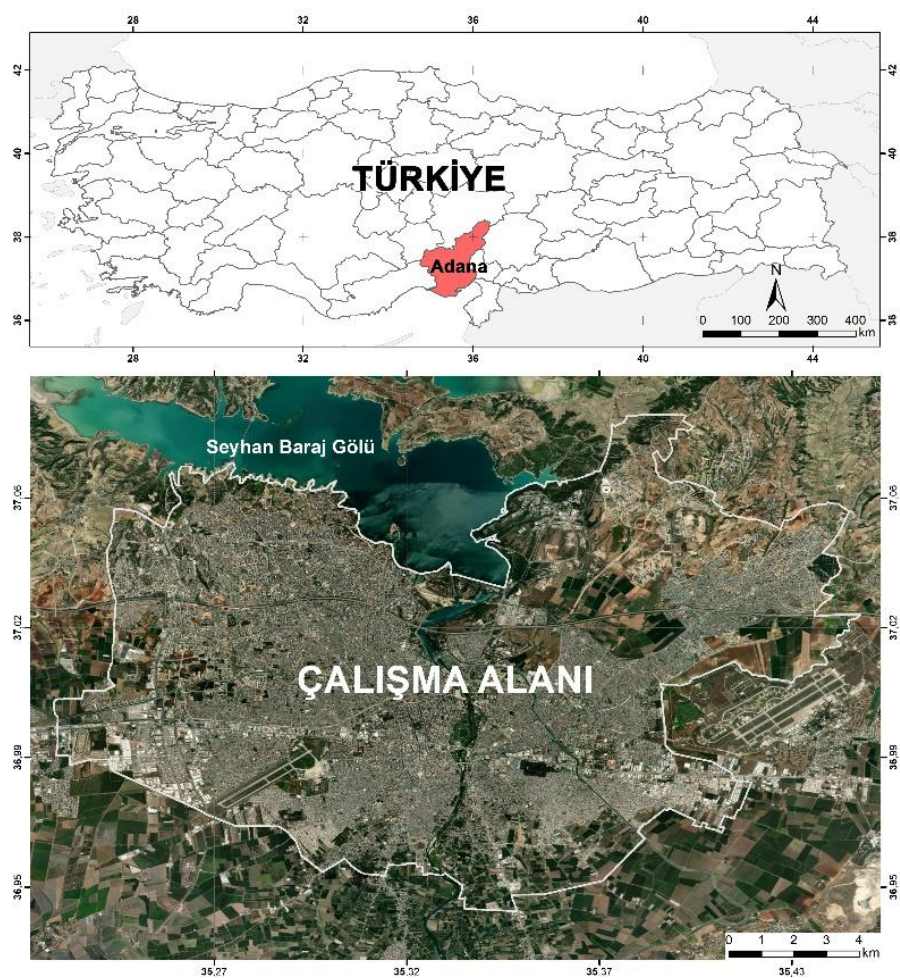

Şekil 1. Çalışma alanı konumu (Figure 1. The location of study area)

Adana, kışları serin ve yağışl1, yazları sıcak ve kurak geçen tipik bir Akdeniz iklimine sahiptir. Ortalama hava sicaklığ 1 Temmuz ve Ağustos aylarında (en sıcak dönem) yaklaşık 34-35 ${ }^{\circ} \mathrm{C}$ ve Ocak ve Şubat aylarında (en soğuk dönem) yaklaşık 14-15 ${ }^{\circ} \mathrm{C}$ 'dir (Şekil 2). Ağustos ayında hava yağışsız ve kuraktır. Bununla birlikte, yıl boyunca günlük ortalama bağıl nem yüksek oranda kalır (\%80'in üzerinde). Adana'da hakim rüzgar yönü kışın kuzey-kuzeydoğu, yazın ise güney-güneybatıdır (Meteoblue.com, 2021). Adana, ülkedeki en verimli tarım arazilerini kapsadığı için tarım ve tarım endüstrileri gelişmiştir. $\mathrm{Bu}$ gelişme, önemli bir istihdam düzeyi yaratmış ve kırsal alanlardan kentsel alanlara yoğun bir iç göç yaşanmasına neden olmuştur (Ünal ve Uslu, 2018). 1980'lerin başında 500.000 olan nüfus, 2018'de yaklaşık 2.220.125'e yükselmiştir (Türkiye İstatistik Kurumu, 2018).

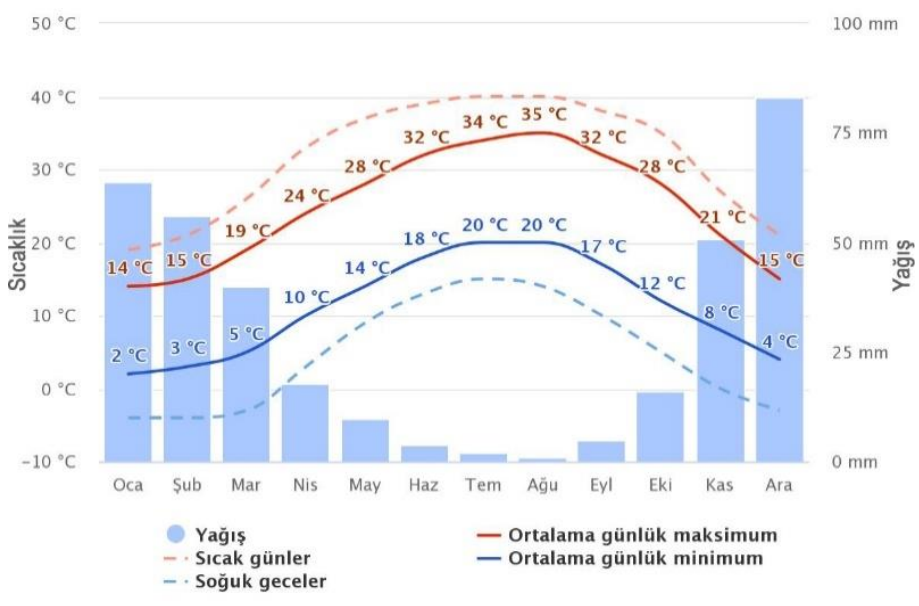

Şekil 2. Son 30 yıllık hava sıcaklığı ve yağış verileri (Figure 2. Air temperature and precipitation data for the last 30 years) (Meteoblue.com, 2021)

\subsection{Veriler}

$\mathrm{Bu}$ çalışmada kentsel alanlardaki AÖ/AK ile YYS arasındaki ilişkiyi incelemek için Landsat 8 OLI ve TIRS verileri kullanılmıştır. Landsat 8 uydusu, Operasyonel Arazi Görüntüleyici (OLI) ve Termal Kızı̈ötesi Sensör (TIRS) olmak üzere iki sensör taşımmaktadır. OLI sensörü görünür, yakın kızılötesi ve kısa dalga boyuna sahip kızılötesinde yedi yansıtıcı band ve ayrıca iki pankromatik ve cirrus bandına sahiptir. TIRS ise termal kızılötesi (TIR) bölgesinde iki banda sahiptir. OLI bandları $30 \mathrm{~m}$, TIRS bandları ise $100 \mathrm{~m}$ yersel çözünürlüğü sahiptir. TIRS bantları, US Geological Survey (USGS) (http://earthexplorer.usgs.gov) tarafından kübik kıvrım (cubic convolution) ile $30 \mathrm{~m}$ yersel çözünürlüğe ölçek küçültme imkânı sağlamaktadır. Landsat 8 OLI/TIRS verileri 2018 yılının AralıkŞubat ayları ve Haziran-Ağustos aylarında elde edilen veriler kullanılarak yaz ve kış sezonu için YYS verileri elde edilmiştir.

Avrupa şehirlerinin derinlemesine analizi için Avrupa Çevre Ajansı (AÇA), Çevre ve Güvenlik için Küresel İzleme (GMES) programı aracılığıyla 2006 yılı için arazi kullanım bilgilerini içeren ücretsiz bir veri seti olan Kentsel Atlası (Urban Atlas) yayınlamıştır. Kentsel Atlas hizmeti, kentsel alanların yüksek çözünürlüklü bir arazi kullanım haritasını sunmaktadır (Şekil 3). Avrupa Birliği ve ülkemizdeki kentler için farklı yapı yoğunluğu seviyelerini temsil eden 20 arazi kullanım sınıfı belirlenmiştir. $\mathrm{Bu}$ çalışmada da Adana kenti için Kentsel Atlas verisi AÇA tarafından elde edilerek YYS analizlerde kullanılmıştır.

\section{ADANA KENT ATLASI ARAZI ÖRTÜSÜ/ARAZI KULLANIMI}

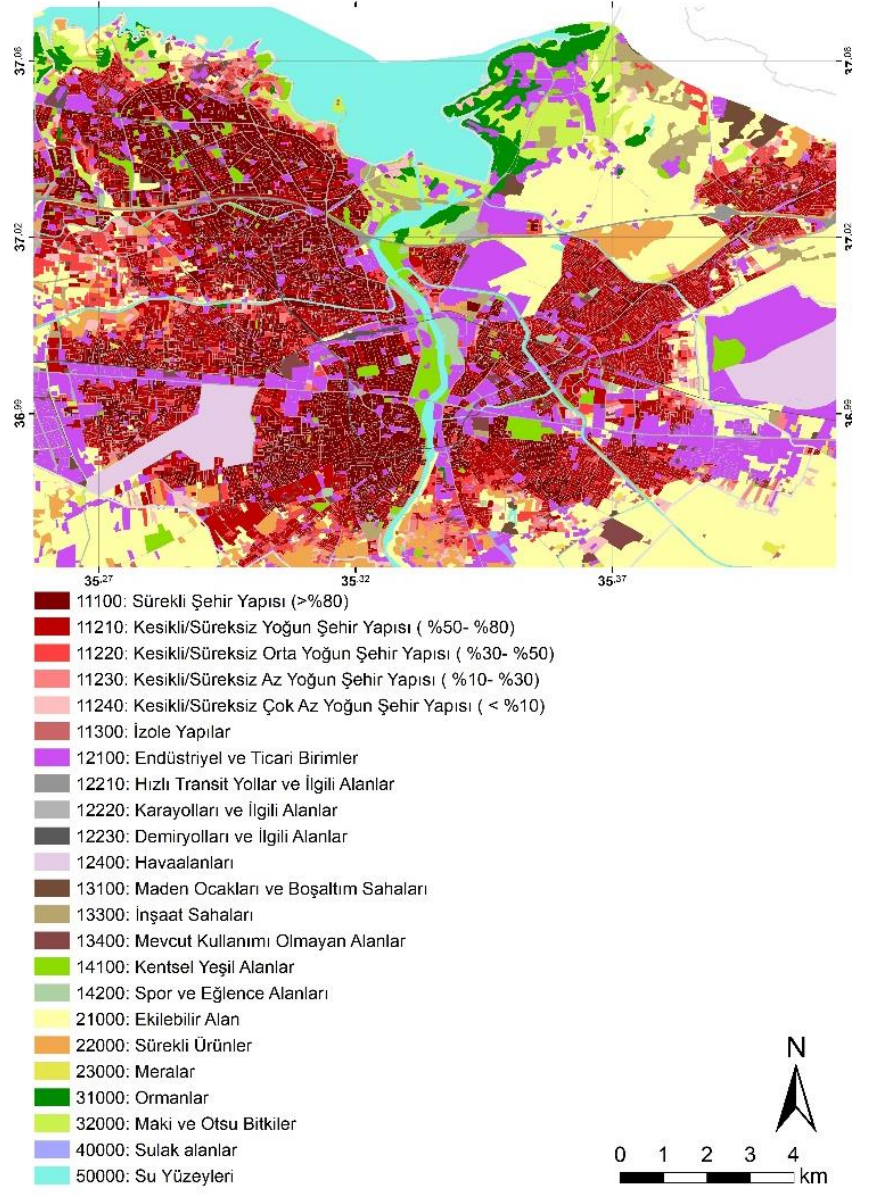

Şekil 3. Adana kenti 2018 yılına ait arazi örtüsü/kullanımı haritas1 (Figure 3. Land cover/use map of Adana City for 2018) (Urban Atlas, 2018) 


\subsection{YYS Verilerin Üretilmesi}

YYS, kentsel 1S1 adasının etkisini ve yüzey-atmosfer etkileşimlerini belirlemek için önemli bir parametre olarak kabul edilmektedir (Dickinson 1994; Zhou ve ark., 2011; Mallick ve ark., 2013). Yer yüzeyi özelliklerinin bileşimi ve fiziksel bileşenleri, kentsel alanın termal modelini belirlemektedir. Uydulardaki kızı̈ötesi sensörler, parlak veya koyu yüzeylerdeki sıcaklıkları elde etmek için atmosfer üstü (TOA) parlaklıkları hesaplamaktadır (Dash ve ark., 2002). Bu parlaklık değerleri LANDSAT 8 OLI ve TIRS bantlarından uzaktan algilama yazılımları aracılığıyla bir dizi hesaplamalar yapılarak YYS verisi elde edebilmek için kullanılmaktadır (Unal Cilek ve Cilek, 2021). Kentsel ve kırsal ortamlar arasındaki iki mekan arasındaki yüzey özelliklerindeki (buharlaşma veya ısı depolama kapasitesi) farklılıkların bir göstergesi olan Normalize edilmiş fark bitki örtüsü indeksi (NDVI) de bu hesaplamalarda kullanılmaktadır.

LANDSAT 8 bandları içerisinden termal bant olarak bant 10 ve NDVI'yi hesaplamak için Band 4 (Kırmızı) ve Band 5 (Yakın kızılötesi) kullanılmaktadır. YYS sıcaklığının üretilmesinde temelde 6 basamaktan oluşmaktadır.

Birinci aşamada Landsat termal bantlarının dijital sayıları (DN) spektral 1şıma veya atmosfer üstü (TOA) spektral parlaklığa dönüştürülmektedir.

$$
T O A(L)=M_{L} * Q_{c a l}+A_{L}
$$

Eşitlik 1'de L, watt/( $\mathrm{m}^{2} *$ ster $\left.* \mu \mathrm{m}\right)$ cinsinden TOA spektral parlaklığını, $M_{L}$ banda özgü çarpımsal yeniden ölçeklendirme faktörünü, $A_{L}$ banda özgü ilave yeniden ölçeklendirme faktörünü, $\mathrm{Q}_{\mathrm{cal}}$ ise düzeltilmiş $\mathrm{DN}$ değeridir.

İkinci aşamada, termal bant verileri, uydu termal sabitleri kullanılarak TOA spektral parlaklığı parlaklık sıcaklığına dönüştürülür. Parlaklık sıcaklığı (BT) değerleri, dünya yüzeyinin kara cisim olarak kabul edildiği spektral parlaklık haritasından ve Landsat veri setinin $\mathrm{K} 1$ ve $\mathrm{K} 2$ kalibrasyon sabitleri kullanılarak tahmin edilmektedir.

$$
B T=\left(K_{2} /\left(\ln \left(K_{1} / L\right)+1\right)\right)-273.15
$$

Eşitlik 2'de BT, TOA parlaklık sıcaklığını temsil eder, $\mathrm{K}_{1}=$ $774.8853\left(\mathrm{watt} /\left(\mathrm{m}^{2} *\right.\right.$ ster $\left.\left.* \mu \mathrm{m}\right)\right)$ ve $\mathrm{K}_{2}=1321.0789$ (Kelvin) kalibrasyon sabitleridir.

Bu hesaplamalar bir kara cisime atıfta bulunulduğundan tüm alanlar için gerçek yüzey sıcaklığını yansıtmaz. Böylece, parlaklık sıcaklığı, arazi örtüsü tipi dikkate alınarak emisyon $(\varepsilon)$ tahmini için de düzeltilmektedir. Üçüncü aşamada, NDVI'dan tahmin edilen bitki örtüsü oranı, yer yüzeyinin emisyonunu ölçmek için bir girdi parametresi olarak kullanılmaktadır. NDVI, yakın kızılötesi (Band 5) ve kırmızı bandın (Band 4) matematiksel işlemi ile elde edilmektedir.

$$
N D V I=(\text { Band } 5-\text { Band } 4) /(\text { Band } 5+\text { Band } 4)
$$

Eşitlik 3 'te NDVI -1 ile 1 arasında bir değer almaktadır. Dördüncü aşamada, NDVI ile yüksek oranda ilişki bulunan bitki örtüsü oranını $\left(\mathrm{P}_{\mathrm{v}}\right)$ ve beşinci aşamada $\mathrm{P}_{\mathrm{v}}$ ile ilişkili olan emisyon oranının ( $\varepsilon$ ) aşağıdaki denklemlerden elde edilmektedir.

$$
\begin{gathered}
P_{v}=\left(\left(N D V I-N D V I_{\min }\right) /\left(N D V I_{\max }-N D V I_{\min }\right)\right)^{2} \\
\varepsilon=0.004 * P_{v}+0.986
\end{gathered}
$$

Son aşamada ise aşağıda gösterildiği gibi TOA parlaklık sıcaklığı ve arazi örtüsü emisyon oranı kullanılarak YYS hesaplanmaktadır.

$$
Y Y S=(B T /(1+(0.00115 * B T / 1.4388) * \operatorname{Ln}(\varepsilon)))
$$

\section{Araştırma Sonuçları}

\subsection{Görüntü Ön İşleme}

Görüntü ön işlemenin amac1, görüntüyü geliștirmek ve/veya belirli işlemler yoluyla görüntüden faydalı bilgiler çıkarmaktır (Basavaprasad ve Ravi, 2014). Bu çalışmada, atmosfer düzeltme ve gürültü azaltma dahil olmak üzere iki ön işleme prosedürü gerçekleştirilmiştir. Atmosfer koşulları, moleküler saçılma ve absorpsiyonun bir sonucu olarak hem uzaysal hem de zamansal olarak değişir (Lu ve ark., 2002). Atmosferik etkiler nedeniyle, uzaktan algılanan bir görüntüdeki herhangi bir pikselde kaydedilen değer, o pikseldeki gerçek yerden ayrılan parlaklığı temsil etmez. $\mathrm{Bu}$ çalışmada kullanılan uydu görüntülerine, Chavez (1996) tarafından önerilen atmosferik düzeltme için karanlık nesne algoritması uygulanmıştır.

2.3 başlığı altında detayları anlatılan aşamalar uygulanarak 2018 yılı için LANDSAT 8 OLI/TIRS verilerinden Aralık-Ocak ve Haziran-Ağustos aylarına ait YYS haritaları üretilmiştir (Şekil 4). YYS sonuçlarına göre kış aylarında sıcaklık $6-22^{\circ} \mathrm{C}$ arasında değişirken, yaz aylarında $22-48^{\circ} \mathrm{C}$ arasında değişmektedir. YYS sıcaklığı en soğuk Ocak ayında meydana gelirken, en sıcak Temmuz ayında meydana gelmiştir. Akarsu ve göl çevrelerinde ise her ayda YYS değerlerinin düşük olduğu görülmektedir.

\subsection{Kent dokusu ile YYS ilişkisi}

Tüm kentsel arazi örtüleri içerisinde endüstriyel ve ticari birimler, kesikli/süreksiz yoğun şehir yapısı (\%50- \%80) ve sürekli şehir yapısı $(>\% 80)$ kentin büyük oranını kapsayan baskın yerleşim bölgeleri olduğu gözlemlenmiştir. Bu üç arazi örtüsü kentin \%63'lük bir alanını kapsamaktadır. Alanın \%16'lık bölümü karayolları ve ilgili alanlarını ve kalan \%21'lik kısmını diğer kentsel arazi örtüleri kapsamaktadır. Kenti kuzey-güney yöneliminde ikiye bölen Seyhan nehri ve etrafında kentsel yeşil alanlar yer almaktadir.

YYS'lerin 2018 yılı için her bir AÖAK türü için tanımlayıcı istatistikleri (ortalama, maksimum, minimum ve standart sapma) analiz edilmiştir. Arazi örtüsü bazında YYS sonuçlarına göre en yüksek YYS'nin sirasiyla havaalanları, endüstriyel ve ticari birimler ile maden ocakları ve boşaltım sahalarında olduğu görülmektedir. En düşük YYS sıcaklıkları ise sırasıyla su yüzeyleri, ormanlar ve kentsel yeşil alanlarıdır.

Şehir yapılarındaki sınıflar ile endüstriyel ve ticari birimler arasında yüzey sıcaklıklarının büyük oranda farklılık belirlenmiştir. Kentsel dokuda şehir yapıları en düşük YYS sıcaklığına sahip alanlar olurken, en yüksek YYS sıcaklığına ticari birimlerin bulunduğu alanlardır (Tablo 1).

Yaz mevsimi için kentsel doku içerisinde en yüksek YYS sıcaklıkları sırasıyla endüstriyel ve ticari birimlerde $\left(47,8^{\circ} \mathrm{C}\right)$, karayolları ve ilgili alanlarda $\left(42{ }^{\circ} \mathrm{C}\right)$, Spor ve eğlence alanlarında $\left(40,1^{\circ} \mathrm{C}\right)$ ve Sürekli şehir yapısında $\left(40,0^{\circ} \mathrm{C}\right)$ görülmüştür. K1ş mevsiminde ise en yüksek sıcaklık kesikli/süreksiz orta yoğun şehir yapısında ( \%30- \%50) (28,4 $\left.{ }^{\circ} \mathrm{C}\right)$, endüstiyel ve ticari birimlerde $\left(24,1{ }^{\circ} \mathrm{C}\right)$ ve izole yapılarda görülmüştür. 
a) KIS MEVSIMI

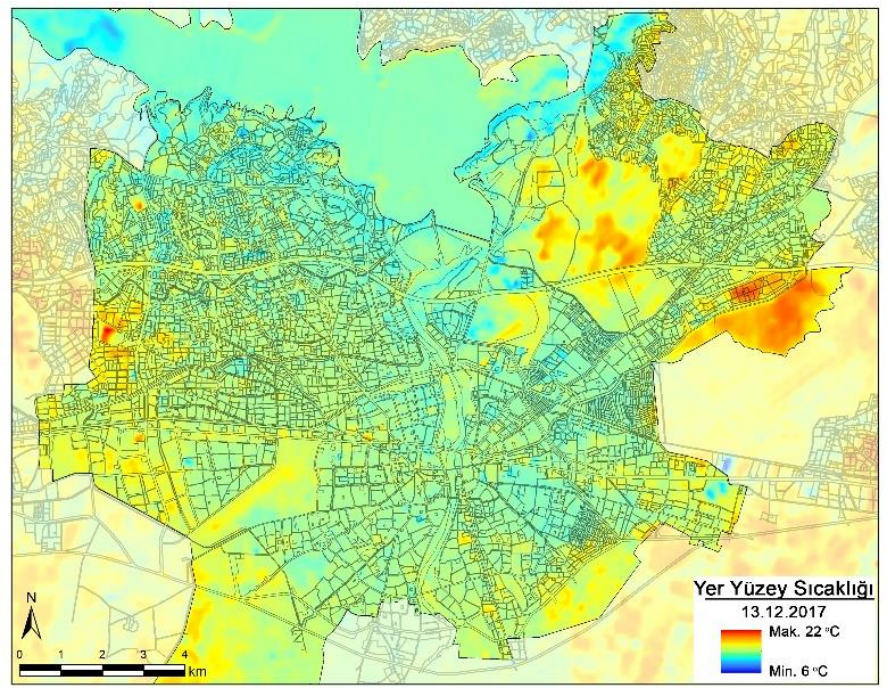

13 Aralık 2017

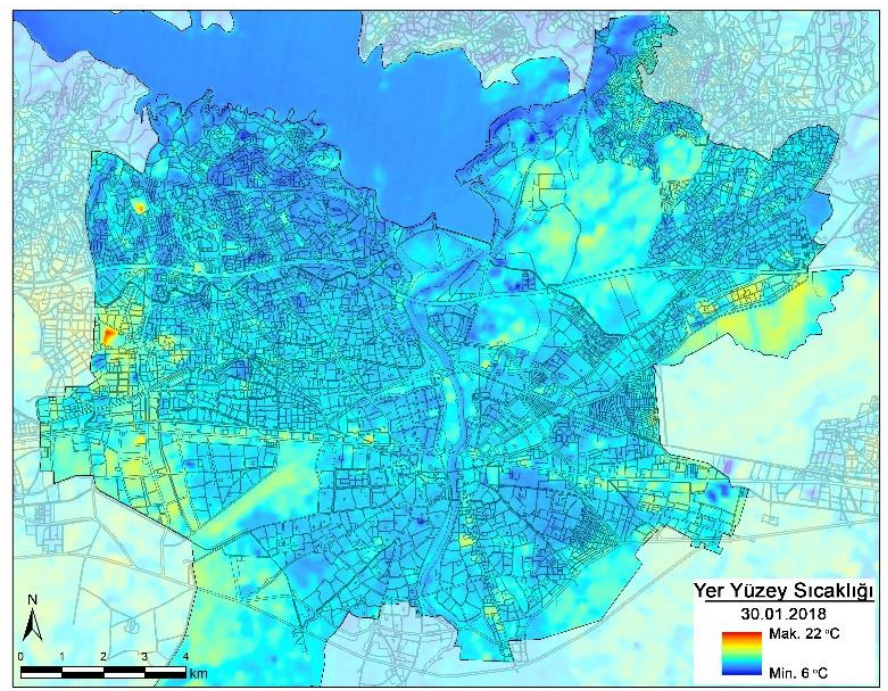

30 Ocak 2018

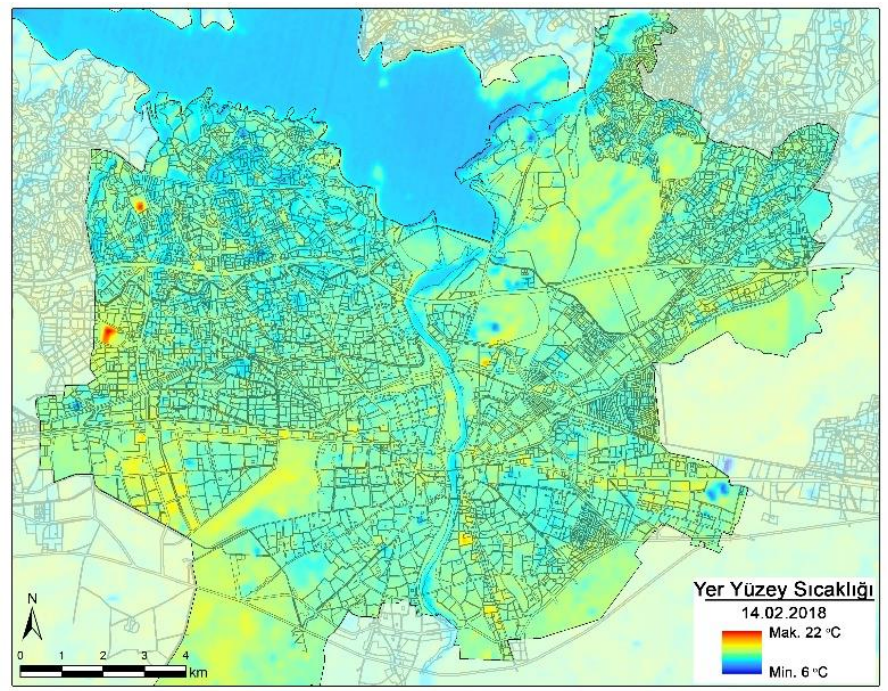

14 Subat 2018 b) YAZ MEVSİMi

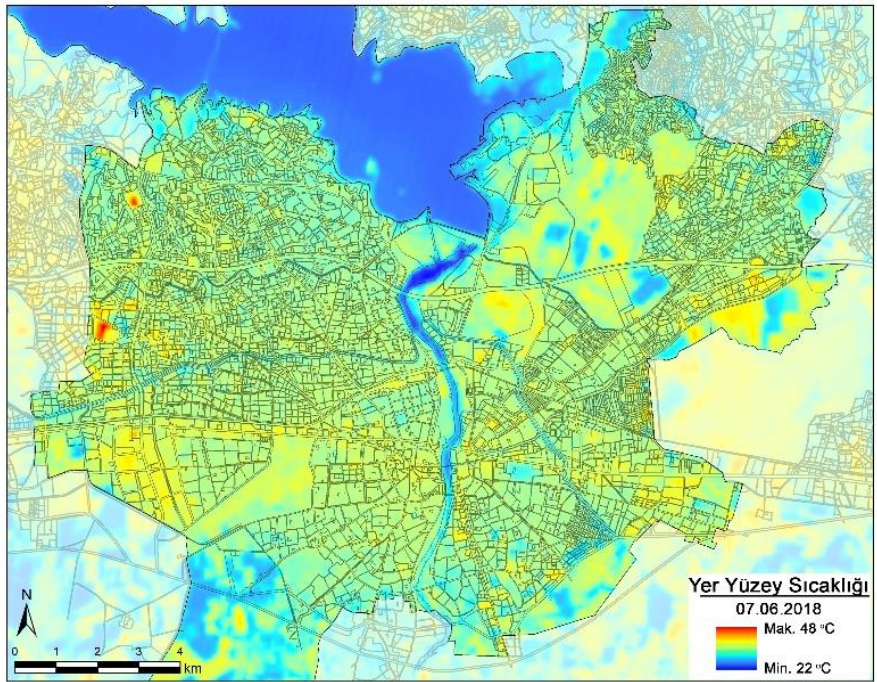

7 Haziran 2018

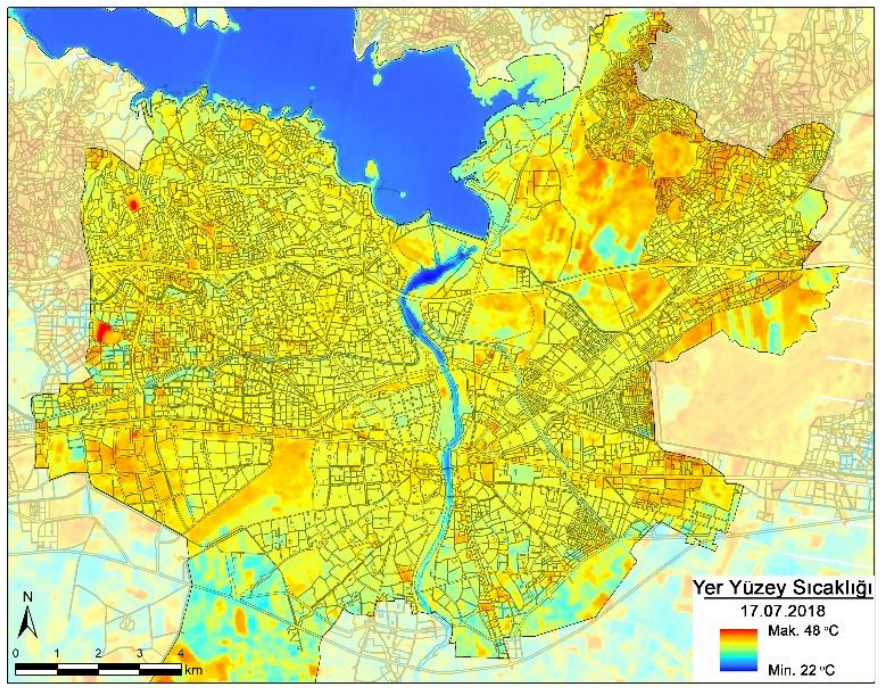

17 Temmuz 2018

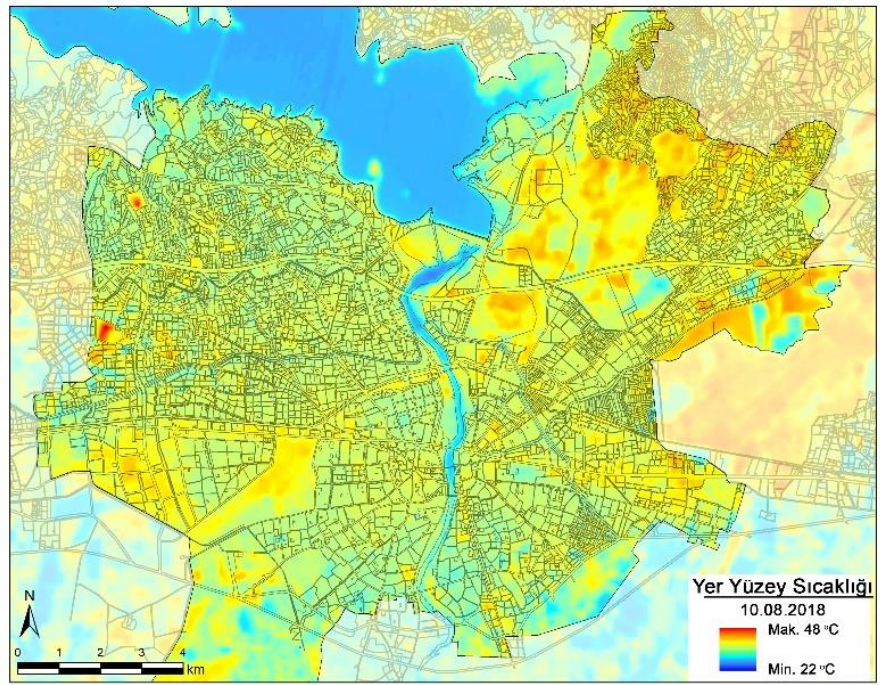

10 Ağustos 2018

Şekil 4. 2018 yılına ait kış mevsimi (a) ve yaz mevsimi (b) aylarına ait YYS haritaları (Figure 4. LST maps of winter (a) and summer (b) months of 2018) 
Tablo 1. AÖAK bazında yaz ve kış aylarında YYS verilerinin istatistiksel sonuçlarl (Table 1. Statistical results of LST data in summer and winter for LULC)

\begin{tabular}{|c|c|c|c|c|c|c|c|c|c|}
\hline \multirow{3}{*}{$\begin{array}{l}\text { AÖAK } \\
\text { Kodu }\end{array}$} & \multirow{3}{*}{ AÖAK Sınıfları } & \multicolumn{8}{|c|}{ Yer Yüzey Sıcaklığı (YYS) } \\
\hline & & \multicolumn{2}{|c|}{$\begin{array}{l}\text { Minimum } \\
{ }^{\circ} \mathrm{C}\end{array}$} & \multicolumn{2}{|c|}{$\begin{array}{l}\text { Maksimum } \\
{ }^{\circ} \mathrm{C}\end{array}$} & \multicolumn{2}{|c|}{$\begin{array}{l}\text { Ortalama } \\
{ }^{\circ} \mathrm{C}\end{array}$} & \multicolumn{2}{|c|}{$\begin{array}{l}\text { Standart } \\
\text { sapma }\end{array}$} \\
\hline & & Kış & Yaz & $\mathrm{K}_{1} \mathbf{s}$ & Yaz & Kış & Yaz & Kış & Yaz \\
\hline 11100 & Sürekli Şehir Yapısı (>\%80) & 13,5 & 30,4 & 22,2 & 40,0 & 17,0 & 33,6 & 0,7 & 0,8 \\
\hline 11210 & Kesikli/Süreksiz Yoğun Şehir Yapısı ( \%50- \%80) & 14,7 & 24,0 & 20,0 & 37,3 & 17,2 & 33,7 & 0,6 & 0,7 \\
\hline 11220 & Kesikli/Süreksiz Orta Yoğun Şehir Yapısı ( \%30- \%50) & 10,6 & 22,8 & 28,4 & 37,4 & 18,1 & 33,7 & 1,2 & 1,0 \\
\hline 11230 & Kesikli/Süreksiz Az Yoğun Şehir Yapısı ( \%10- \%30) & 14,9 & 26,2 & 20,3 & 38,0 & 17,2 & 33,8 & 0,5 & 1,5 \\
\hline 11240 & Kesikli/Süreksiz Çok Az Yoğun Şehir Yapısı ( <\%10) & 12,3 & 27,7 & 19,9 & 38,8 & 17,5 & 33,8 & 0,8 & 1,4 \\
\hline 11300 & İzole Yapılar & 13,7 & 27,8 & 22,1 & 37,7 & 18,8 & 34,0 & 1,2 & 1,5 \\
\hline 12100 & Endüstriyel ve Ticari Birimler & 13,6 & 22,5 & 24,1 & 47,8 & 17,4 & 35,1 & 0,8 & 1,9 \\
\hline 12210 & Hızlı Transit Yollar ve İlgili Alanlar & 15,1 & 27,6 & 20,8 & 37,2 & 17,9 & 34,7 & 0,7 & 1,1 \\
\hline 12220 & Karayolları ve İlgili Alanlar & 13,3 & 20,8 & 20,0 & 42,0 & 17,0 & 33,9 & 0,9 & 1,2 \\
\hline 12230 & Demiryolları ve İlgili Alanlar & 14,4 & 23,1 & 21,4 & 37,9 & 17,9 & 34,6 & 0,9 & 1,3 \\
\hline 12400 & Havaalanları & 13,7 & 28,7 & 19,9 & 39,3 & 17,5 & 36,8 & 0,9 & 1,1 \\
\hline 13100 & Maden Ocakları ve Boşaltım Sahaları & 13,0 & 25,2 & 20,1 & 39,6 & 17,0 & 35,0 & 1,1 & 2,2 \\
\hline 13300 & İnşaat Sahaları & 14,1 & 20,5 & 20,5 & 38,8 & 18,0 & 35,0 & 1,0 & 1,8 \\
\hline 13400 & Mevcut Kullanımı Olmayan Alanlar & 14,1 & 21,0 & 20,8 & 38,4 & 17,7 & 34,5 & 0,8 & 1,3 \\
\hline 14100 & Kentsel Yeşil Alanlar & 13,8 & 21,2 & 21,5 & 37,3 & 17,7 & 32,3 & 0,9 & 2,0 \\
\hline 14200 & Spor ve Eğlence Alanları & 14,8 & 21,9 & 20,6 & 40,1 & 18,0 & 34,2 & 1,0 & 1,7 \\
\hline 21000 & Ekilebilir Alan & 13,0 & 25,7 & 20,8 & 39,8 & 14,2 & 34,4 & 1,4 & 1,6 \\
\hline 22000 & Sürekli Ürünler & 11,9 & 22,5 & 21,1 & 39,7 & 18,8 & 33,0 & 1,4 & 1,6 \\
\hline 23000 & Meralar & 13,0 & 27,3 & 21,1 & 39,1 & 15,7 & 34,4 & 1,2 & 1,4 \\
\hline 31000 & Ormanlar & 14,7 & 20,9 & 20,8 & 37,0 & 17,7 & 30,4 & 1,1 & 1,8 \\
\hline 32000 & Maki ve Otsu Bitkiler & 14,8 & 20,7 & 19,7 & 38,5 & 17,9 & 33,6 & 0,6 & 2,1 \\
\hline 40000 & Sulak alanlar & 16,9 & 24,9 & 20,4 & 35,3 & 18,9 & 33,3 & 0,5 & 1,5 \\
\hline 50000 & Su Yüzeyleri & 16,8 & 18,6 & 18,6 & 37,0 & 17,6 & 22,7 & 0,5 & 4,4 \\
\hline
\end{tabular}

\subsection{SUHI'nin mevsimsel varyasyonlarının analizi}

KIA hava sıcaklığı ve YYS temelinde iki açıdan değerlendirilebilir (Das ve Das, 2020a). Bu çalışmada, KIA kent dokusu da YYS temelinde değerlendirilmiştir. Bir kentsel alandaki 1sınma etkisi, yoğun kentsel yerleşim alanı ve düşük yoğun kentsel arazi kullanımı pikselleri arasındaki yüzey sıcaklık farkı olarak hesaplanan kentsel yüzey 1sı adası (SUHI) yoğunluğu sigmoid aktivasyonu ile ölçülebilir:

$$
\underset{\text { aktivasyonu }}{\text { Sigmoid }}=\frac{Y Y S_{i}-Y Y S_{\text {düşük slcakllk }}}{Y Y S_{\text {yüksek slcakllk }}-Y Y S_{\text {düşük slcakllk }}}
$$

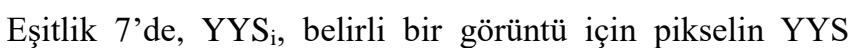

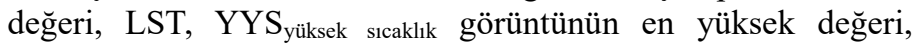

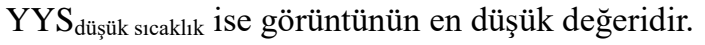

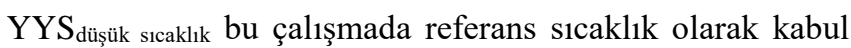
edilmiştir ve kentsel alanı çevreyelen birkaç km'lik tampon alandaki pikseller üzerinden ortalama YYS'den hesaplanmıştır. Su yüzeyleri, bitki örtüsü ve tarım arazileri gibi diğer arazi kullanımları çok yüksek veya çok düşük YYS kaydettiği için bu alanlar dikkate alınmamıştır. SUHI yoğunluğu yerel hava durumlarından ve diğer kaynaklardan büyük ölçüde etkilendiği için mutlak sıcaklık olarak kabul edilmez. Çalışmanın bu bölümünde, SUHI'nin elde edilmesi ve yaz ve kış mevsiminde mekansal değişimi incelenmiştir. Sonuçlardan, kentsel dokuda SUHI yoğunluğunda mevsimsel varyasyonlar meydana geldiği görülmektedir (Şekil 5).

Her bir kentsel arazi örtüsü sınıfı için termal dağılımın konumsal analiz etmek için arazi kullanım haritaları SUHI yoğunluğu haritası ile ilişkilendirilmiştir. Sonuçlara göre, yüksek SUHI yoğunluğunun yerleşik alanlarda kış ve yaz mevsimlerinde özellikle sert zemin oranının yüksek olduğu havalimanı ile endüstriyel ve ticari birimlerde yoğunlaştığı kaydedilmiştir. Endüstriyel ve ticari alanlarda sert zemin oranının yüksek olmasının yanı sıra bu alanda yer alan yapıların kat yüksekliğinin düşük olması bu alanların güneş maruziyetini arttırmakta ve SUHI indeksini etkilemektedir. Hem yaz hemde kış mevsimleri için maksimum SUHI yoğunluğuna bakıldığında şehir yapısında geçirimsiz yüzeylerde (endüstri alanları, karayolları, havaalanları, vb.) yüksek oranda SUHI yoğunluğunun bulunduğu görülmektedir

Yoğun yerleşim alanlarında ise bu durum tam tersidir. Özellikle yüksek katlı yerleşim bölgelerinde (Kuzey Adana) SUHI sıcaklığının en düşük olduğu gözlemlenmiştir. Bunun temel sebebi yüksek katlı yerleşim alanlarında veya düşük katlı yoğun yerleşim dokusuna sahip alanlarda binalardan kaynaklı gölge oranının yüksek olması ve bina çevresinde bulunan bitki 218 
örtüsünden kaynaklı değişkenlerin olmasıdır. $\mathrm{Bu}$ yüzden değerlendirmeye dahil edilen iki periyot için minimum SUHI yoğunluğu sürekli şehir yapısı veya kesikli/süreksiz yoğun ve orta yoğun şehir yapısında ortaya çıkmaktadır (Tablo 2).

a)

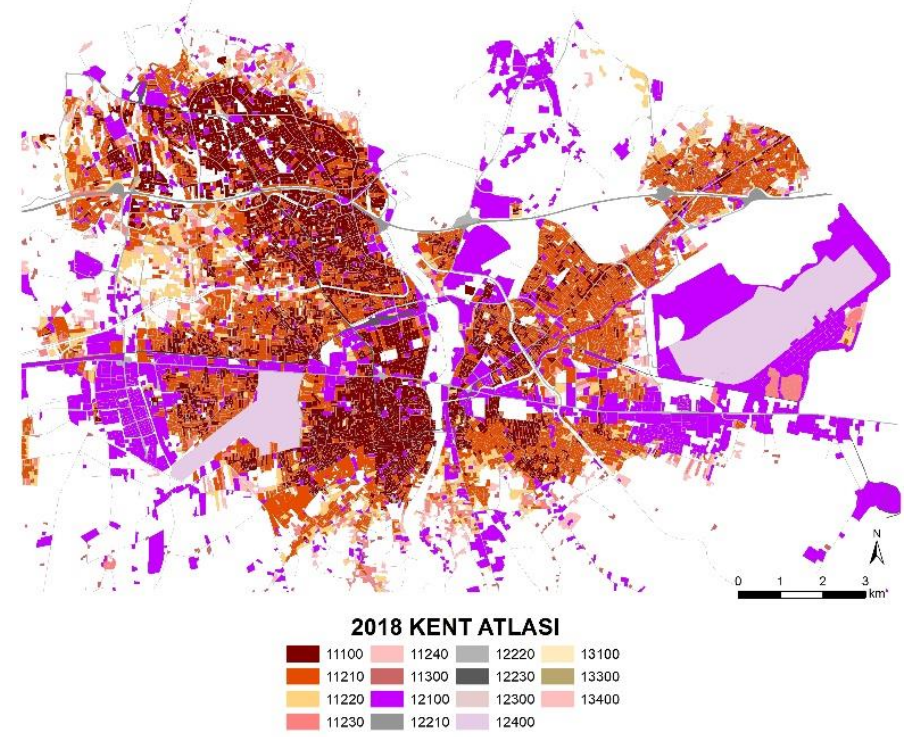

b)

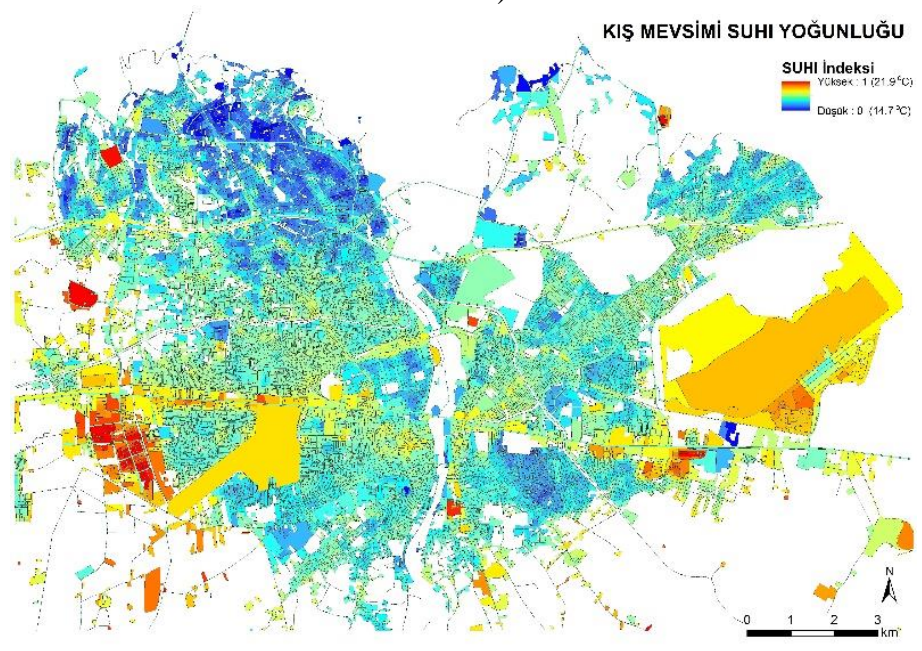

c)

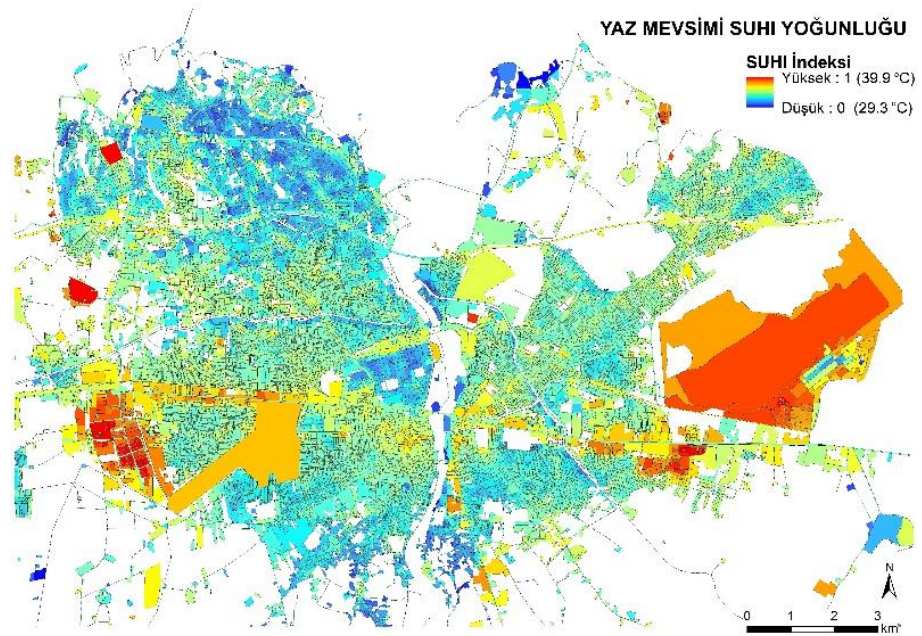

Şekil 5. (a) Kentsel doku, (b) Kış mevsimi SUHI yoğunluğu, (c) yaz mevsimi SUHI yoğunluğu haritaları (Figure 5. The maps of (a) urban atlas, (b) winter SUHI density, and (c) summer SUHI density)
Tablo 2. AÖAK bazında yaz ve klş aylarında SUHI yoğunluğunun istatistiksel sonuçlarl (Table 2. Statistical results of SUHI density in summer and winter season for LULC)

\begin{tabular}{|c|c|c|c|c|c|c|c|c|}
\hline \multirow{3}{*}{$\begin{array}{l}\text { AÖAK } \\
\text { Kodu }\end{array}$} & \multirow{3}{*}{ AÖAK Sınıfları } & \multirow{3}{*}{$\begin{array}{l}\text { Alan } \\
\text { (ha) }\end{array}$} & \multicolumn{6}{|c|}{ SUHI Yoğunluğu } \\
\hline & & & \multicolumn{2}{|c|}{$\underset{{ }^{\circ} \mathrm{C}}{\operatorname{Minimum}}$} & \multicolumn{2}{|c|}{$\begin{array}{l}\text { Maksimum } \\
{ }^{\circ} \mathrm{C}\end{array}$} & \multicolumn{2}{|c|}{$\begin{array}{l}\text { Ortalama } \\
{ }^{\circ} \mathrm{C}\end{array}$} \\
\hline & & & $\mathrm{K}_{1 S ̧}$ & Yaz & $\mathrm{K}_{1 S ̧}$ & Yaz & Kiş & Yaz \\
\hline 11100 & $\begin{array}{l}\text { Sürekli Şehir Yapısı } \\
(>\% 80)\end{array}$ & 2213 & 0,00 & 0,20 & 0,7 & 0,8 & 0,3 & 0,4 \\
\hline 11210 & $\begin{array}{l}\text { Kesikli/Süreksiz } \\
\text { Yoğun Şehir Yapısı } \\
(\% 50-\% 80)\end{array}$ & 2715 & 0,05 & 0,00 & 0,7 & 0,7 & 0,3 & 0,4 \\
\hline 11220 & $\begin{array}{l}\text { Kesikli/Süreksiz Orta } \\
\text { Yoğun Şehir Yapısı } \\
(\% 30-\% 50)\end{array}$ & 730 & 0,13 & 0,15 & 0,6 & 0,6 & 0,3 & 0,4 \\
\hline 11230 & $\begin{array}{l}\text { Kesikli/Süreksiz Az } \\
\text { Yoğun Şehir Yapısı } \\
(\% 10-\% 30)\end{array}$ & 444 & 0,07 & 0,14 & 0,6 & 0,8 & 0,4 & 0,4 \\
\hline 11240 & $\begin{array}{l}\text { Kesikli/Süreksiz Çok } \\
\text { Az Yoğun Şehir } \\
\text { Yapısı }(<\% 10)\end{array}$ & 329 & 0,08 & 0,10 & 0,6 & 0,8 & 0,4 & 0,4 \\
\hline 11300 & İzole Yapılar & 68 & 0,04 & 0,15 & 0,7 & 0,8 & 0,5 & 0,4 \\
\hline 12100 & $\begin{array}{l}\text { Endüstriyel ve Ticari } \\
\text { Birimler }\end{array}$ & 3234 & 0,00 & 0,12 & 1,0 & 1,0 & 0,5 & 0,5 \\
\hline 12210 & $\begin{array}{l}\text { Hizlı Transit Yollar } \\
\text { ve İlgili Alanlar }\end{array}$ & 117 & 0,32 & 0,38 & 0,5 & 0,5 & 0,4 & 0,5 \\
\hline 12220 & $\begin{array}{l}\text { Karayolları ve İlgili } \\
\text { Alanlar }\end{array}$ & 2083 & 0,25 & 0,33 & 0,5 & 0,6 & 0,4 & 0,4 \\
\hline 12230 & $\begin{array}{l}\text { Demiryolları ve İlgili } \\
\text { Alanlar }\end{array}$ & 90 & 0,38 & 0,44 & 0,5 & 0,6 & 0,4 & 0,5 \\
\hline 12400 & Havaalanları & 929 & 0,55 & 0,63 & 0,6 & 0,7 & 0,6 & 0,7 \\
\hline
\end{tabular}

\section{Sonuç}

Çalışma, kış (Aralık-Ocak-Şubat) ve yaz ayları (HaziranTemmuz-Ağustos) olmak üzere iki dönem için AÖAK ile YYS arasındaki ilişkinin değerlendirilmesine odaklanmayı amaçlamıştır. SUHI'nin mevsimsel değişimleri de kent dokusu arasında mekansal varyasyonunun yakından anlaşılması için değerlendirilmiştir. Kentsel dokudaki geçirgen yüzeylerin geçirimsiz yüzeylere hızlı bir şekilde dönüştürülmesi, termal ortamların değişmesine ve ardından 1sı dalgalarının ortaya çıkmasına neden olmaktadır. Bu durum, insan sağlığının aşırı sıcaktan büyük ölçüde etkilenmesi nedeniyle olumsuz etkileri de beraberinde getirmektedir (Liu ve ark., 2017; Pantavou ve ark., 2017; Massey ve ark., 2016; Janssen ve ark., 2012; Hajat ve ark., 2007; Kunst ve ark., 1993; Kyselý ve Huth; 2004). Bu çalışmada da geniş geçirimsiz yüzeylere sahip olan havalimanı ile endüstriyel ve ticari birimlerinde SUHI yoğunluğunun yüksek olduğu görülmüştür. Bu alanlarda YYS sıcaklığının azaltılması SUHI ve SUHI'nin insan sağlığı üzerine olumsuz etkisinin azaltacaktır. Bu bağlamda kentsel sürdürülebilirlik için iklime duyarlı planlamaya etkin bir şekilde odaklanılması ve kentler üzerindeki termal ısı davranış kalıplarının değerlendirilmesi için gelecekteki kentsel iklim yönetimine yardımcı olacak kentsel planlama ve politikalarda sürdürülebilir önemli bir veri sağlanmıştır.

\section{Kaynakça}

Agarwal, R., Sharma, U., \& Taxak, A. (2014). Remote sensing based assessment of urban heat island phenomenon in 
Nagpur Metropolitan Area. International Journal of Computers and Technology, 4(11), 10691074.

Arifwidodo, S. D., \& Chandrasiri, O. (2020). Urban heat stress and human health in Bangkok, Thailand. Environmental Research, 185(March), 109398. https://doi.org/10.1016/j.envres.2020.109398.

Basavaprasad, B., Ravi, M., 2014. A study on the importance of image processing and its applications. Int. J. Res. Eng. Technol. 3.

Chavez, P.S., 1996. Image-based atmospheric correctionsrevisited and improved. Photogramm. Eng. Remote. Sens. 62 (9), 1025-1035.

Chen, Y.C., Chiu, H.W., Su, Y.F., Wu, Y.C., Cheng, K.S., 2017. Does urbanization increase diurnal land surface temperature variation? Evidence and implications. Landsc. Urban Plan. 157, 247-258.

Das, M., Das, A., 2019a. Estimation of ecosystem services (EESs) loss due to transformation of LCZs(LCZs) in sriniketan-santiniketan planning area (SSPA) West Bengal, India. Sustainable Cities and Society 47, 101474. https://doi.org/ 10.1016/j.scs.2019.101474.

Das, M., Das, A., 2019b. Dynamics of Urbanization and its impact on urban ecosystem services (UESs): a study of a medium size town of West Bengal, Eastern India. Journal of Urban Management 8 (3), 420-434.

Das, M., Das, A., 2020a. Assessing the relationship between local climatic zones (LCZs) and land surface temperature (LST) -A case study of Sriniketan-Santiniketan Planning Area (SSPA), West Bengal, India. Urban Climate 32, 100591. https://doi. org/10.1016/j.uclim.2020.100591.

Das, M., Das, A., Mandal, S., 2020b. Outdoor thermal comfort in different settings of a tropical planning region of Eastern India by adopting LCZs approach: a case study on Sriniketan-Santiniketan Planning Area (SSPA). Sustainable Cities and Society 102433. https://doi.org/10.1016/j.scs.2020.102433

Dash, P., Gottsche, F. -M., Olesen, F. -S., \& Fischer, H. (2002). Land surface temperature and emissivity estimation from passive sensor data: Theory and practice-current trends. International Journal of Remote Sensing, 23(13), 2563-2594.

Dickinson, R.E., 1994. Satellite systems and models for future climate change. In: Henderson-Sellers, A. (Ed.), Future Climates of the World: A Modelling Perspective.Elsevier, pp. 27 16, World Survey of Climatology.

Diem, J. E., Stauber, C. E., \& Rothenberg, R. (2017). Heat in the southeastern United States: Characteristics, trends, and potential health impact. PLoS ONE, 12(5), 1-19. https://doi.org/10.1371/journal.pone.0177937

Dong,W., Liu, Z., Zhang, L., Tang, Q., Liao, H., Li, X., 2014. Assessing heat health risk for sustainability in Beijing's urban heat island. Sustainability 6, 7334-7357.

Du, H., Zhou, F., Li, C., Cai,W., Jiang, H., Cai, Y., 2020. Analysis of the impact of land use on spatiotemporal patterns of surface urban heat island in rapid urbanization, a case study of Shanghai, China. Sustainability 12, 1171.
Dutta, I., Das, A., 2020. Exploring the Spatio-temporal pattern of regional heat island (RHI) in an urban agglomeration of secondary cities in Eastern India. Urban Climate 34, 100679. https://doi.org/10.1016/j.uclim.2020.100679.

Estoque, R.C., Murayama, Y., Myint, S.W., 2017. Effects of landscape composition and pattern on land surface temperature: an urban heat island study in the megacities of Southeast Asia. Sci. Total Environ. 577, 349-359.

Fonseka, H.P.U., Zhang, H., Sun, Y., Su, H., Lin, H., Lin, Y., 2019. Urbanization and its impacts on land surface temperature in Colombo metropolitan area, Sri Lanka, from 1988 to 2016 . Rem. Sens. 11 (8), 957.

Guo, Z., Wang, S.D., Cheng, M.M., Shu, Y., 2012. Assess the effect of different degrees of urbanization on land surface temperature using remote sensing images. Procedia Environmental Sciences 13, 935-942.

Hajat, S., Kovats, R.S., Lachowycz, K., 2007. Heat-related and cold-related deaths in England and Wales: who is at risk? Occup. Environ. Med. 64 (2), 93-100. https:// doi.org/10.1136/oem.2006.029017

Heaviside, C., Vardoulakis, S., \& Cai, X. M. (2016). Attribution of mortality to the urban heat island during heatwaves in the West Midlands, UK. Environmental Health: A Global Access Science Source, 15(Suppl 1). https://doi.org/10.1186/s12940-016- 0100-9.

Hirano, Y., \& Fujita, T. (2012). Evaluation of the impact of the urban heat island on residential and commercial energy consumption in Tokyo. Energy, 37(1), 371-383. https://doi.org/10.1016/j.energy.2011.11.018

Janssen, N.A.H., Gerlofs-Nijland, M.E., Lanki, T., Salonen, R.O., Cassee, F., Hoek, G., et al., 2012. Health Effects of Black Carbon, the WHO European Centre for Environment and Health. World Health Organisation Regional Office for Europe, Copenhagen, Denmark. Bonn, Germany

Jiang, Y., Fu, P., Weng, Q., 2015. Assessing the impacts of urbanization-associated land use/cover change on land surface temperature and surface moisture: a case study in the midwestern United States. Rem. Sens. 7 (4), 4880-4898.

Kunst, A.E., Looman, C.W., Mackenbach, J.P., 1993. Outdoor air temperature and mortality in The Netherlands: a timeseries analysis. Am. J. Epidemiol. 137 (3), 331-341. https://doi.org/10.1093/oxfordjournals.aje.a116680

Kysely, J., Huth, R., 2004. Heat-related mortality in the Czech Republic examined through synoptic and traditional1 approaches. Clim. Res. 25 (3), 265-274. https:// doi.org/10.3354/cr025265.

Li, Z.L., Tang, B.H., Wu, H., Ren, H., Yan, G., Wan, Z., ... Sobrino, J.A., 2013. Satellite-derived land surface temperature: Current status and perspectives. Remote sensing of environment 131, 14-37.

Li, G., Zhang, F., Jing, Y., Liu, Y., Sun, G., 2017. Response of evapotranspiration to changes in land use and land cover and climate in China during 2001-2013. Sci. Total Environ. 596, 256-265.

Lu, D., Mausel, P., Brondizio, E., Moran, E., 2002. Assessment of atmospheric correction methods for Landsat TM data 
applicable to Amazon basin LBA research. Int. J. Remote Sens. 23 (13), 2651-2671.

Macintyre, H. L., Heaviside, C., Cai, X., \& Phalkey, R. (2021). The winter urban heat island: Impacts on cold-related mortality in a highly urbanized European region for present and future climate. Environment International, 154, Article 106530. https:// doi.org/10.1016/j.envint.2021.106530

Mallick, J., Rahman, A., Singh, C.K., 2013. Modeling urban heat islands in heterogeneous land surface and its correlation with impervious surface area by using night-time ASTER satellite data in highly urbanizing city, Delhi-India. Adv. $\begin{array}{llll}\text { Space } & \text { Res. } & 52 & \text { (4), }\end{array}$ https://doi.org/10.1016/j.asr.2013.04.025.

Massey, D.D., Habil, M., Taneja, A., 2016. Particles in different indoor microenvironments-its implications on occupants. Build. Environ. 106, 237-244. https://doi.org/10.1016/j.buildenv.2016.06.036

Mathew, A., Sreekumar, S., Khandelwal, S., Kaul, N., Kumar, R., 2016. Prediction of surface temperatures for the assessment of urban heat island effect over Ahmedabad city using linear time series model. Energy Build. 128, 605-616. https://doi.org/ 10.1016/j.enbuild.2016.07.004.

Melaas, E.K., Wang, J.A., Miller, D.L., Friedl, M.A., 2016. Interactions between urban vegetation and surface urban heat islands: a case study in the Bostonmetropolitan region. Environ. Res. Lett. 11, 054020.

Meteoblue.com, 2021. Adana iklim verileri (Erişim tarihi: 16 Kasim 2021)

Oke, T.R., 1973. City size and the urban heat island. Atmos. Environ. 7 (8), 769-779. https://doi.org/10.1016/00046981(73)90140-6, 1967.

Oke, T. R. (1982). The energetic basis of the urban heat island. Quarterly Journal of the Royal Meteorological Society, 108(455), 1-24. https://doi.org/10.1002/ qj.49710845502

Pantavou, K., Lykoudis, S., Psiloglou, B., 2017. Air quality perception of pedestrians in an urban outdoor Mediterranean environment: a field survey approach. Sci. Total Environ. 574 , 663-670.

https://doi.org/10.1016/j.scitotenv.2016.09.090

Patz, J. A., Campbell-Lendrum, D., Holloway, T., \& Foley, J. A. (2005). Impact of regional climate change on human health. Nature, 438(7066), 310-317. https://doi.org/ 10.1038 /nature 04188

Ramamurthy, P., Sangobanwo, M., 2016. Inter-annual variability in urban heat island intensity over 10 major cities in the United States. Sustain. Cities Soc. 26, 65-75.

Rasul,A., Balzter, H., Smith,C., Remedios, J., Adamu, B., Sobrino, J., Srivanit, M., Weng, Q. (2017). A review on remote sensing of urban heat and cool islands, Land 638 , https://doi.org/10.3390/land6020038

Santamouris, M., Cartalis, C., Synnefa, A., 2015. Local urban warming, possible impacts and a resilience plan to climate change for the historical center of Athens, Greece. Sustainable Cities and Society 19, 281-291. https://doi.org/10.1016/j. scs.2015.02.001
Santamouris, M. (2013). Using cool pavements as a mitigation strategy to fight urban heat island - A review of the actual developments. Renewable and Sustainable Energy Reviews, 26, 224-240. https://doi.org/10.1016/i.rser.2013.05.047.

Santamouris, M. (2014) On the energy impact of urban heat island and global warming on buildings, Energy Build. 82,100-113, https://doi.org/10.1016/j. enbuild.2014.07.022.

Sarrat, C., Lemonsu, A., Masson, V., Guedalia, D., 2006. Impact of urban heat island on regional atmospheric pollution. Atmos. Environ. 40, 1743-1758

Stathopoulou, E., Mihalakakou, G., Santamouris, M., \& Bagiorgas, H. S. (2008). On the impact of temperature on tropospheric Ozone concentration levels in urban environments. Journal of Earth System Science, 117(3), 227-236. https://doi.org/ 10.1007/s12040-008-0027-9

Stewart, I. D., \& Oke, T. R. (2012). Local climate zones for urban temperature studies. Bulletin of the American Meteorological Society, 93(12), 1879-1900. https://doi.org/ 10.1175/BAMS-D-11-00019.1

Sun, Y., \& Augenbroe, G. (2014). Urban heat island effect on energy application studies of office buildings. Energy and Buildings, 77, 171-179. https://doi.org/10.1016/j. enbuild.2014.03.055

Tan, J., Zheng, Y., Tang, X., Guo, C., Li, L., Song, G., Zhen, X., Yuan, D., Kalkstein, A. J., Li, F., \& Chen, H. (2010). The urban heat island and its impact on heat waves and human health in Shanghai. International Journal of Biometeorology, 54(1), 75-84. https://doi.org/10.1007/s00484-009-0256-X

Tan, J., Zheng, Y., Tang, X., Guo, C., Li, L., Song, G., Zhen, X., Yuan, D., Kalkstein, A.J., Li, F., Chen, H., 2010. The urban heat island and its impact on heatwaves and human health in Shanghai. Int. J. Biometeorol. 54, 75-84.

Tayyebi, A., Shafizadeh-Moghadam, H., Tayyebi, A.H., 2018. Analyzing long-term spatio-temporal patterns of land surface temperature in response to rapid urbanization in the mega-city of Tehran. Land Use Pol. 71, 459-469.

Urban Atlas, 2018. Urban Atlas Database. Copernicus Copernicus Land Monitoring Service.

Unal Cilek, M., Cilek, A., 2021. Analyses of land surface temperature (LST) variability among local climate zones (LCZs) comparing Landsat-8 and ENVI-met model data. Sustain. Cities Soc. 69, 102877. https://doi.org/10.1016/j.scs.2021.102877.

Unated Nations, 2018. 2018 Revision of World Urbanization Prospects. https://population.un.org/wup/.

Ünal, M., Uslu, C. (2018) Evaluating and optimizing urban green spaces for compact urban areas: Cukurova District in Adana, Turkey. ISPRS International Journal of GeoInformation 7:70.

Vandentorren, S., Bretin, P., Zeghnoun, A., Mandereau Bruno, L., Croisier, A., Cochet, C., Riberon, J., Siberan, I., Declercq, B., Ledrans, M., 2006. August 2003 heat wave in France: risk factors for death of elderly people living at home. Eur. J. Pub. Health 16, 583-591 
Voogt, J. A., \& Oke, T. R. (2003). Thermal remote sensing of urban climates. Remote Sensing of Environment, 86(3), 370 384.

Wan, Z., \& Li, Z. L. (1997). A physics-based algorithm for retrieving land-surface emissivity and temperature from eos/modis data. IEEE Transactions on Geoscience and Remote Sensing : A Publication of the IEEE Geoscience and Remote Sensing Society, 35(4), 980-996.

Wang, W., Yao, X., \& Shu, J. (2020). Air advection induced differences between canopy and surface heat islands. Science of the Total Environment, 725, Article 138120. https://doi.org/10.1016/j.scitotenv.2020.138120

Wemegah, C. (2020). Systematic assessment of Urban Heat Island (UHI) warming in systematic assessment of Urban Heat Island (UHI) warming in greater Accra region. [place unknown]. Ghana: Kwame Nkrumah University of Science and Technology.

Weng, Q., Rajasekar, U., \& Hu, X. (2011). Modeling Urban Heat Islands and Their Relationship With Impervious Surface and Vegetation Abundance by Using ASTER Images. IEEE Transactions on Geoscience and Remote Sensing : A Publication of the IEEE Geoscience and Remote Sensing Society, 49(2), 4080-4089.

Yang, J., Sun, J., Ge, Q., Li, X., 2017. Assessing the impacts of urbanization-associated green space on urban land surface temperature: a case study of Dalian, China. Urban For. Urban Green. 22, 1-10.

Yu, X., Guo, X., Wu, Z., 2014. Land surface temperature retrieval from Landsat 8 TIRS - comparison between radiative transfer equation-based method, split window algorithm and single channel method. Rem. Sens. 6 (10), 9829-9852. https://doi. org/10.3390/rs6109829

Zhou,W., Pickett, S.T.A., Cadenasso,M.L., 2016. Shifting concepts of urban spatial heterogeneity and their implications for sustainability. Land. Ecol. 32, 15-30

Zhou, D., Xiao, J., Bonafoni, S., Berger, C., Deilami, K., Zhou, Y., Frolking, S., Yao, R., Qiao, Z., \& Sobrino, J. A. (2019). Satellite remote sensing of surface urban heat islands: Progress, challenges, and perspectives. Remote Sensing, 11(1), 1-36. https:// doi.org/10.3390/rs11010048.

Zhou, W., Pickett, S.T.A., McPhearson, T., 2021. Conceptual frameworks facilitate integration for transdisciplinary urban science. npj Urban Sustainability, 1.

Zhou, W., Huang, G., \& Cadenasso, M. L. (2011). Does spatial configuration matter? Understanding the effects of land cover pattern on land surface temperature in urban landscapes. Landscape and Urban Planning, 102(1), 54-63. https://doi.org/10.1016/ j.landurbplan.2011.03.009

Zipper, S. C., Schatz, J., Singh, A., Kucharik, C. J., Townsend, P. A., \& Loheide, S. P. (2016). Urban heat island impacts on plant phenology: Intra-urban variability and response to land cover. Environmental Research Letters, 11(5). https://doi.org/ 10.1088/1748-9326/11/5/054023. 